\title{
Generation and evaluation of A2-expressing Lactococcus lactis live vaccines against Leishmania donovani in BALB/c mice
}

Correspondence

Benoit Cousineau

benoit.cousineau@mcgill.ca

Received 5 January 2011

Accepted 23 April 2011

\author{
Karen K. Yam, ${ }^{1}$ Felix Hugentobler, ${ }^{1}$ Philippe Pouliot, ${ }^{1}$ Andrew M. Stern, ${ }^{1}$ \\ Jean-Daniel Lalande, ${ }^{1}$ Greg Matlashewski, ${ }^{1}$ Martin Olivier ${ }^{1,2}$ \\ and Benoit Cousineau ${ }^{1}$
}
${ }^{1}$ Department of Microbiology and Immunology, McGill University, 3775 University Street, Montreal, OC H3A 2B4, Canada
${ }^{2}$ Centre for the Study of Host Resistance, Research Institute of the McGill University Health Centre, Montreal, Quebec, Canada

\begin{abstract}
Leishmaniasis is a parasitic disease affecting over 12 million individuals worldwide. As current treatments are insufficient, the development of an effective vaccine is a priority. This study generated and assessed the efficacy of Leishmania vaccines engineered from the non-colonizing, non-pathogenic Gram-positive bacterium Lactococcus lactis. A truncated, codon-optimized version of the A2 antigen from Leishmania donovani was engineered for expression in Lactococcus lactis in three different subcellular compartments: in the cytoplasm, secreted outside the cell or anchored to the cell wall. These three A2-expressing Lactococcus lactis strains were tested for their ability to generate A2-specific immune responses and as live vaccines against visceral Leishmania donovani infection in BALB/c mice. Subcutaneous immunization with live Lactococcus lactis expressing A2 anchored to the cell wall effectively induced high levels of antigen-specific serum antibodies. It was demonstrated that Lactococcus lactis-based vaccines are a feasible approach in the generation of live vaccines against leishmaniasis. The Lactococcus lactis strains generated in this study provide an excellent foundation for further studies on live bacterial vaccines against leishmaniasis and other pathogens.
\end{abstract}

\section{INTRODUCTION}

The parasite Leishmania affects over 12 million individuals worldwide and manifests as three forms of disease: cutaneous, mucocutaneous and visceral leishmaniasis, the last usually being fatal (reviewed by Kedzierski et al., 2006). Current treatments are insufficient and consist primarily of highly toxic chemotherapy. Furthermore, there are now many instances of parasite resistance to the available treatments (Kedzierski et al., 2006). Therefore, a vaccine that can prevent the occurrence and reduce the spread of the disease is a priority in this field. The ability to develop protective immunity against leishmaniasis following deliberate inoculation with live parasites, known as leishmanization, has demonstrated that the creation of an effective vaccine against leishmaniasis is possible (Khamesipour et al., 2005).

Abbreviations: ABTS, 2,2'-azino-bis(3-ethylbenzthiazoline-6-sulfonic acid); cwa, cell-wall anchoring; FBS, fetal bovine serum; HRP, horseradish peroxidase; IFN- $\gamma$, gamma interferon; IL, interleukin; LDU, Leishman-Donovan units; p.i., post-infection; SLA, soluble Leishmania antigen; Th, T helper; wt, wild-type.
A potential vaccine antigen against leishmaniasis is the amastigote-specific A2 family of proteins, which were identified in Leishmania donovani (Charest \& Matlashewski, 1994). The A2 proteins contain an N-terminal signal peptide, followed by a variable number of repeats of a 10 aa sequence and a 7 aa C-terminal region (Charest \& Matlashewski, 1994). As a result, in Leishmania donovani, wild-type A2 proteins (wtA2) vary in size from 45 to $100 \mathrm{kDa}$, representing 40-90 repeats (Fig. 1a). Analysis of Leishmania genomic DNA has shown that A2 is found in strains that cause both visceral (Leishmania donovani, Leishmania infantum and Leishmania chagasi) and cutaneous (Leishmania amazonensis and Leishmania mexicana) leishmaniasis (Garin et al., 2005; Ghedin et al., 1997). However, the A2 gene is present in Leishmania major as nonexpressed pseudo-genes (Zhang et al., 2003). A2 contributes to the ability of some Leishmania parasites to infect visceral organs and is therefore considered a putative virulence factor (Garin et al., 2005; Zhang \& Matlashewski, 2001; Zhang et al., 2003). This antigen was found to be protective in recombinant protein vaccines in various vaccine mouse models, including against cutaneous and visceral leishmaniasis caused by Leishmania amazonensis (Coelho et al., 2003) 
and Leishmania donovani (Ghosh et al., 2001a, b), respectively. In addition, the $\mathrm{A} 2$ antigen was protective in mice when expressed as a recombinant adenovirus vaccine (Resende et al., 2008) and when expressed in the nonpathogenic Leishmania tarentolae strain as a live heterologous vaccine (Mizbani et al., 2009), and was shown to provide some protection in dogs as a recombinant protein vaccine (Fernandes et al., 2008).

Lactococcus lactis is an industrially important Gram-positive lactic acid bacterium that is frequently used in the preparation of fermented foods (Beresford et al., 2001). As this bacterium is found in and consumed as part of various food products, we know that it is non-pathogenic and noncolonizing, and therefore it was given Generally Recognized As Safe (GRAS) status by the US Food and Drug Administration (Casalta \& Montel, 2008; FDA, 1995). Recently, Lactococcus lactis was used as a live bacterial vector to deliver various biological molecules (Steidler, 2003). Studies in which Lactococcus lactis was engineered to express vaccine antigens such as fragment $\mathrm{C}$ of the tetanus toxin (Robinson et al., 2004), the E7 antigen of human papilloma virus (Cortes-Perez et al., 2003) and many other bacterial, viral and parasitic antigens have shown that this is an effective strategy to generate live heterologous vaccines (Detmer \& Glenting, 2006). Furthermore, we have demonstrated that Lactococcus lactis exhibits innate inflammatory effects and the ability to modulate dendritic cell maturation, which indicate a capacity for adjuvanticity (Yam et al., 2008). These properties strengthen the rationale for using Lactococcus lactis as a live vaccine vector.

In this study, we engineered strains of Lactococcus lactis to express a codon-optimized and truncated form of the Leishmania A2 protein at different subcellular locations: in the cytoplasm, secreted outside the cell and anchored to the cell wall. These strains of A2-expressing Lactococcus lactis were tested as live bacterial vaccines against visceral Leishmania donovani infection in $\mathrm{BALB} / \mathrm{c}$ mice. We demonstrate that Lactococcus lactis-based vaccines are a feasible approach in the generation of live vaccines against leishmaniasis.

\section{METHODS}

Bacterial strains and growth conditions. Escherichia coli strains DH5 $\alpha$ (Invitrogen) and BL21(DE3) (Novagen EMD Chemicals) were used for DNA cloning and purification of His-tagged proteins, respectively, and were grown with shaking in LB broth (Wisent) at $37^{\circ} \mathrm{C}$. Lactococcus lactis subsp. cremoris NZ9000 (Kuipers et al., 1998) was grown without shaking in M17 medium (Oxoid) with $0.5 \%$ glucose (GM17) at $30{ }^{\circ} \mathrm{C}$. This strain of Lactococcus lactis is a plasmid-free derivative of the dairy starter strain NCDO71 that is suitable for use as a live vaccine vector (Mierau \& Kleerebezem, 2005). Antibiotics were added at the following concentrations: $100 \mu \mathrm{g}$ ampicillin $\mathrm{ml}^{-1}$ and $300 \mu \mathrm{g}$ spectinomycin $\mathrm{ml}^{-1}$.

Plasmid construction. The pDL278 plasmid (LeBlanc et al., 1992) was used for A2 expression in Lactococcus lactis. A nisin-controlled gene expression system was selected, as higher levels of heterologous protein are achieved with an inducible rather than a constitutive promoter (Bermúdez-Humarán et al., 2004). The nisin-inducible promoter, $\mathrm{P}_{\text {nisA }}$ (Kuipers et al., 1995), was PCR amplified to add an NsiI restriction site at the starting ATG (Table 1) and was cloned into pDL278 at the unique EcoRI site (Table 2, pDL- $\mathrm{P}_{\text {nisA }}$ ). A 25 bp spacer region containing a unique $B s g I$ restriction site was cloned into the NsiI site of the promoter (Table 1, annealed oligonucleotides; Table 2, pDL- $\left.\mathrm{P}_{\text {nisA }} \mathrm{B}\right)$. The wild-type A2 from Leishmania donovani consists of an $\mathrm{N}$-terminal leader sequence followed by tandem repeats of a 10 aa dominant epitope. The 10 aa wild-type A2 repeat was codon optimized for overexpression in Lactococcus lactis; of the ten amino acids, eight were coded by the most rarely used codon in Lactococcus lactis. All codons were exchanged with the most commonly used counterpart in Lactococcus lactis. The first A2 repeat was generated by a pair of complementary oligonucleotides (Table 1) cloned downstream of the $\mathrm{P}_{n i s A}$ promoter using the $B s g \mathrm{I}$ restriction enzyme, which cuts $12 / 14 \mathrm{nt}$ upstream of its recognition site (Table 2, pDL-P $\mathrm{P}_{n i s A^{-}}$ cytoA $2_{1}$ ). Subsequently, annealed oligonucleotide pairs corresponding to two A2 repeats (Table 1) were consecutively added at the BsgI site to generate our synthetic A2 protein (Table 2, pDL- $\mathrm{P}_{n i s A^{-}}$ cytoA $2_{3}$ ). The largest construct stably isolated in E. coli consisted of ten tandem repeats of the 10 aa $\mathrm{A} 2$ epitope $\left(\mathrm{A} 2_{10}\right)$. The $\mathrm{A} 2_{10}$ gene (315 bp, $105 \mathrm{aa}$ ) located directly downstream of the $\mathrm{P}_{\text {nisA }}$ promoter corresponded to cytoplasmic expression in Lactococcus lactis (Table 2, pDL-P ${ }_{\text {nis }}$-cytoA2 10 ).

The secretion signal of Usp45 from Lactococcus lactis (125 bp) was PCR amplified from pCWA:E7 (Table 1), kindly provided by P. Langella (Le Loir et al., 1998; Ribeiro et al., 2002), and was cloned into the NsiI site between the promoter and the $\mathrm{A} 2$ gene to direct protein expression into the culture medium (Table 2, pDL- $\mathrm{P}_{\text {nisA }}$-secA2 $2_{10}$ ).

Finally, to direct A2 to be anchored to the cell wall of Lactococcus lactis, the cell-wall anchoring (cwa) domain of the M6 protein of Streptococcus pyogenes (475 bp) (Piard et al., 1997; Ribeiro et al., 2002) was added to the $3^{\prime}$ end of the A2 gene, in addition to the $5^{\prime}$-end secretion signal. A unique NheI restriction site was engineered at the $3^{\prime}$ end of the A2 gene. A pair of annealed oligonucleotides corresponding to one A2 repeat followed directly by the NheI site (Table 1) was cloned into the BsgI site of a construct containing only nine tandem repeats of the 10 aa $\mathrm{A} 2$ epitope. This resulted in the same A2 gene as above but with a unique NheI site (Table 2, pDL- $\mathrm{P}_{n i s}-\mathrm{cytoA} 2{ }_{10} \mathrm{~N}$ ). The cwa domain was PCR amplified from pCWA:E7 to include flanking NheI sites (Table 1) and was cloned downstream of A2. The addition of the secretion signal and the cwa domain $5^{\prime}$ and $3^{\prime}$ to the gene, respectively, directed A2 protein expression to be anchored to the cell wall (Table 2, pDL-P ${ }_{\text {nisA }}-\mathrm{CwaA2} 2_{10}$ ).

To create a His-tagged version of A2 for protein purification, the cytoA2 gene was excised with $\mathrm{NsiI}$ and $\mathrm{Bsg}$ I and blunt cloned into the plasmid pET-16b (Table 2; Novagen) digested with XhoI and BamHI. This strategy maintained the ORF of the His tag with the gene and resulted in the entire synthetic $\mathrm{A} 2$ protein, consisting of ten 10 aa repeats, attached to an N-terminal $10 \times$ His tag of the plasmid (Table 2, pET-A2 $2_{10}$ ). The pET-16b-based plasmid containing the His-tagged version of the wildtype A2 gene from Leishmania donovani (Table 2, pET-wtA2) has been described previously (Charest \& Matlashewski, 1994).

Restriction enzymes were purchased from New England Biolabs. All plasmid constructs were confirmed by DNA sequencing and transferred into Lactococcus lactis by electroporation, as described previously (Wells et al., 1993).

Protein expression, purification and immunoblotting. Histagged protein purification from E. coli was performed according to the manufacturer's protocol (Novagene). Saturated overnight cultures of $E$. coli were diluted $1: 100$ in fresh medium and grown until they reached an $\mathrm{OD}_{600}$ of 0.4-0.5. Protein expression was induced by the 
(a)

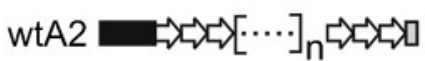

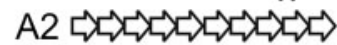

(d)

\section{Plasmid}

pDL278

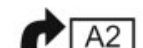

pDL-P nisA-cytoA210 $_{10}$
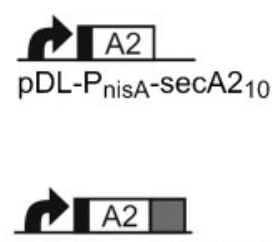

pDL-P nisA-CwaA2 $_{10}$

\section{Schematic and Strain Name}<smiles>C1CCCCC1</smiles>

L. lactis / vector

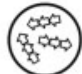

L. lactis / cytoA2

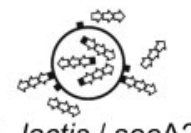

L. lactis / secA2

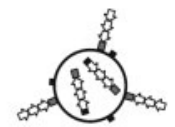

L. lactis / cwaA2 (b)

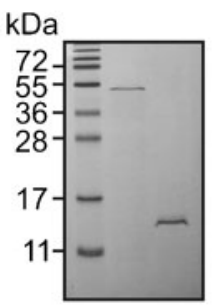

(c)

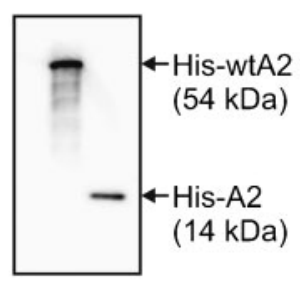

(e)

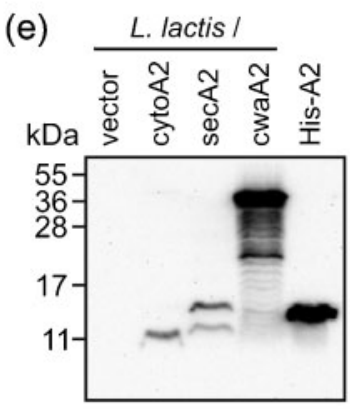

(f) L. lactis /

$\frac{\overline{\text { cytoA2 }}}{\mathrm{PW} S} \frac{\mathrm{sec} A 2}{\mathrm{PW} S} \frac{\mathrm{CWaA2}}{\mathrm{PW} S}$

(g)
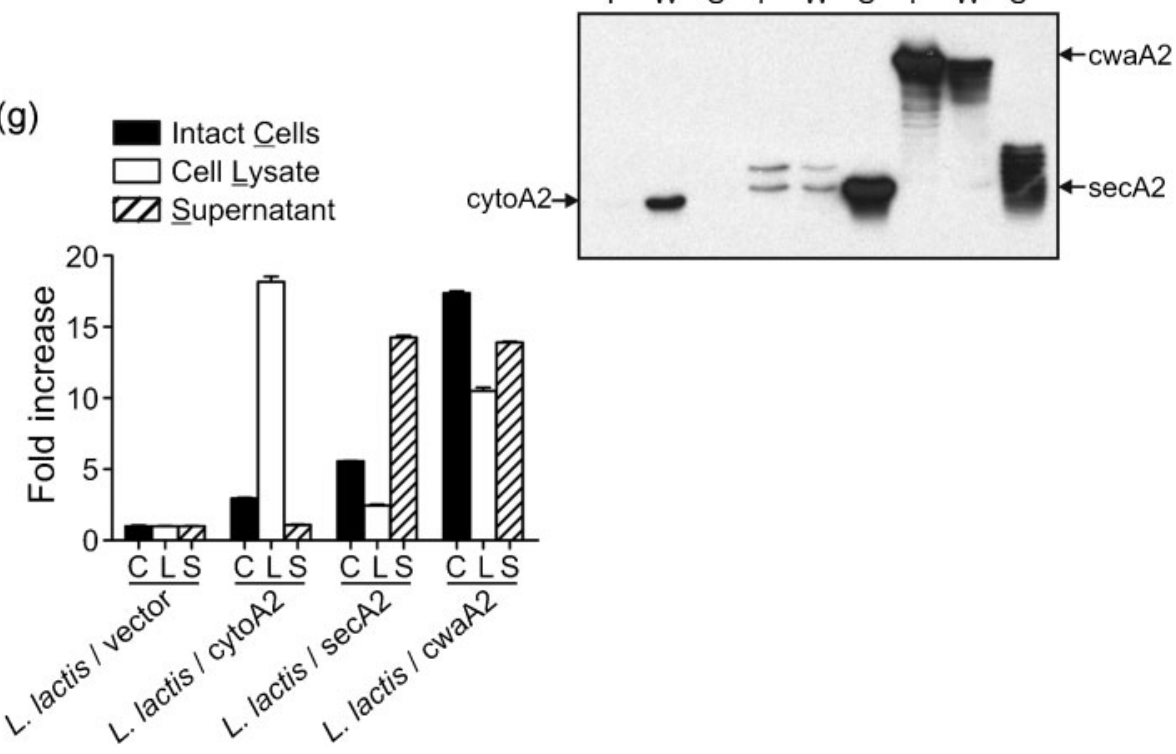

Fig. 1. Generation, expression and localization of a synthetic $A 2$ protein in $E$. coli and in three subcellular compartments of Lactococcus lactis, and comparison of the wild-type A2 gene from Leishmania spp. (wtA2) and our synthetic A2 gene (A2), which was expressed in E. coli and Lactococcus lactis. Strains of Lactococcus lactis expressing A2 in the cytoplasm, secreted into the supernatant and anchored to the cell wall were generated in this study. (a) Schematic representation of the wtA2 and A2 genes. Filled box, putative secretion signal; open arrows, 10 aa dominant epitope of A2; shaded box, 7 aa C-terminal region. (b) Coomassie blue-stained SDS-polyacrylamide gel of His-purified wtA2 (His-wtA2) and synthetic A2 (His-A2) expressed in E. coli. (c) Western blot analysis of the purified A2 proteins using A2-specific antibodies. (d) Lactococcus lactis plasmid constructs, schematic representations of expression strategies and strain names. Arrow, nisin-inducible promoter $\left(P_{\text {nis } A}\right)$; open box, synthetic A2 gene; filled box, Usp45 secretion signal; shaded box, M6 cell-wall anchoring domain. (e) Western blot analysis of total protein extracts of A2-expressing strains of Lactococcus lactis. (f) Cell fractionation and Western blot analysis of A2 expression in Lactococcus lactis. P, Protoplast; W, cell-wall fraction; S, supernatant; cytoA2, cytoplasmic A2; secA2, secreted A2; cwaA2, cell-wall-anchored A2. (g) Whole-cell ELISA analysis of the localization of A2 in Lactococcus lactis. Data presented are the fold increase compared with Lactococcus lactis containing the empty vector (Lactococcus lactis/vector) for each compartment. C, Intact cells; L, heat-killed cell lysate; S, culture supernatant. 
Table 1. Primers used in this study

F, forward; R, reverse; T, top; B, bottom.

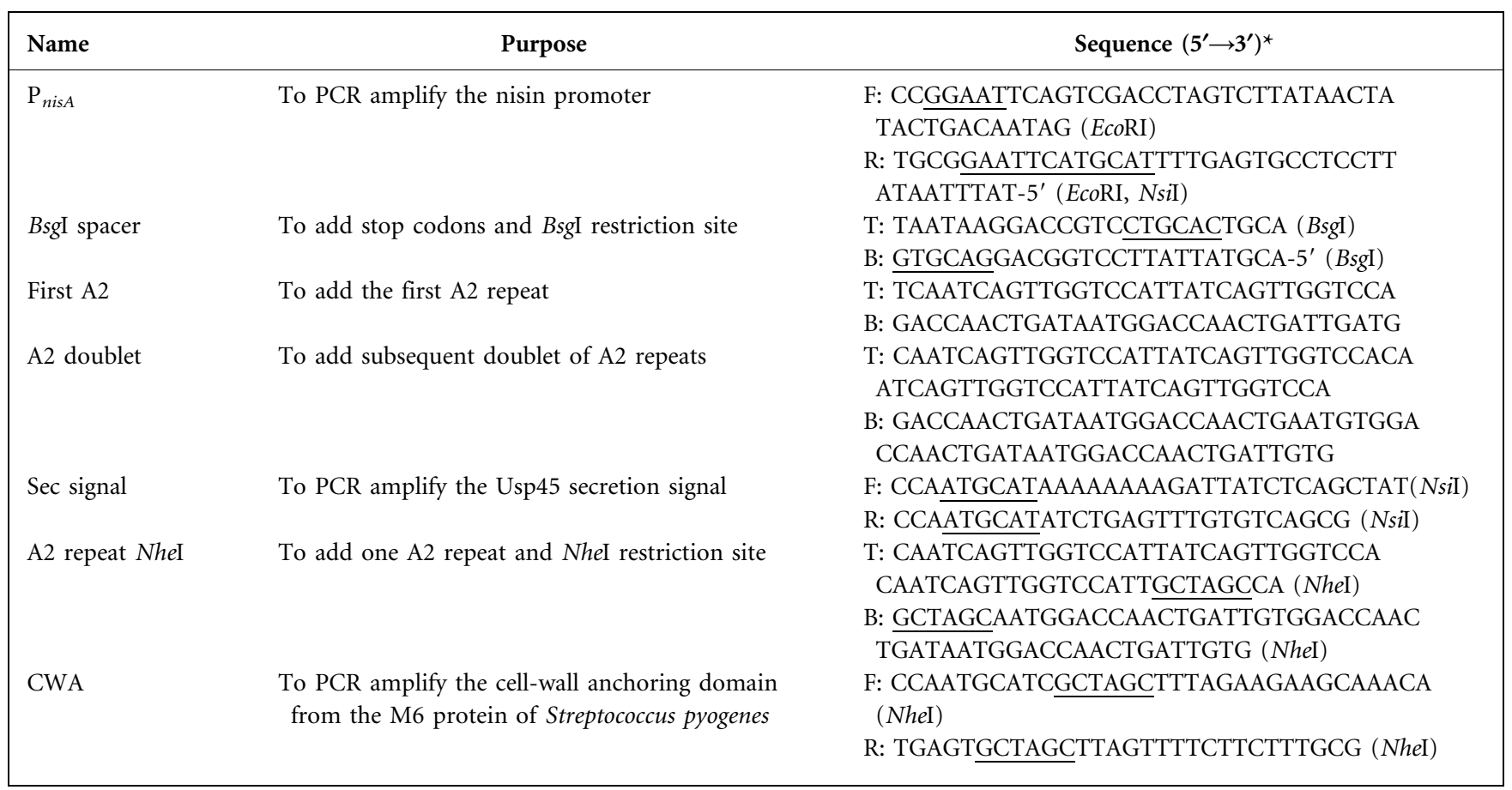

${ }^{\star}$ Underlined nucleotides signify locations of restriction sites (enzyme indicated in parentheses).

addition of $1 \mathrm{mM}$ IPTG and cultures were grown for an additional $3 \mathrm{~h}$.

Saturated overnight cultures of Lactococcus lactis were diluted $1: 20$ in fresh medium and grown to $\mathrm{OD}_{600} 0.4-0.5$. Protein expression was induced by the addition of nisin $\left(10 \mathrm{ng} \mathrm{ml}^{-1}\right.$, maximal subinhibitory concentration) and cultures were grown for an additional $3 \mathrm{~h}$. We found that growth for $3 \mathrm{~h}$, following nisin induction, allowed the highest level of protein accumulation within bacterial cells (data not shown). Following protein expression, cultures $(2 \mathrm{ml})$ were subjected to a total cell protein extract or a cell fractionation protocol, essentially as described previously (Piard et al., 1997). In both cases, bacterial cells were collected by centrifugation $\left(4300 \mathrm{~g}, 10 \mathrm{~min}, 4{ }^{\circ} \mathrm{C}\right)$ and washed with TES [10 mM Tris/HCl (pH 8.0), 1 mM EDTA, $25 \%$ sucrose]. For the total cell extract, cells were resuspended in TES-LMR (TES with $1 \mathrm{mg}$ lysozyme $\mathrm{ml}^{-1}, 50 \mathrm{U}$ mutanolysin $\mathrm{ml}^{-1}$ and $0.1 \mathrm{mg}$ RNaseA $\mathrm{ml}^{-1}$ ) and incubated at $37^{\circ} \mathrm{C}$ for $1 \mathrm{~h}$ to digest the cell wall. Cells were lysed in TE buffer with $2 \%$ SDS and then incubated in boiling water for $5 \mathrm{~min}$. For the cell fractionation, following centrifugation, the culture supernatant was recovered and was precipitated on ice with $10 \%$ TCA for $1 \mathrm{~h}$. The protein pellet was collected by centrifugation in a microcentrifuge (13000 r.p.m., $15 \mathrm{~min}, 4{ }^{\circ} \mathrm{C}$ ) and washed with cold acetone. The pellet was dried briefly and resuspended in $50 \mathrm{mM}$ $\mathrm{NaOH}$. The cell pellet was washed with TES, resuspended in TES-LMR and incubated at $37^{\circ} \mathrm{C}$ for $1 \mathrm{~h}$, as described above. The protoplast (pellet) was collected by centrifugation $\left(2000 \mathrm{~g}, 15 \mathrm{~min}, 4^{\circ} \mathrm{C}\right)$, whilst the supernatant corresponded to the proteins released from the cell wall (cell-wall fraction). Protoplasts were lysed in TE buffer with $2 \%$ SDS and then incubating in boiling water for $5 \mathrm{~min}$. The cell-wall fraction was TCA precipitated as for the culture supernatant fraction and resuspended in $50 \mathrm{mM} \mathrm{NaOH}$.

Protein preparations were resolved by $18 \%$ SDS-PAGE and stained with Coomassie blue or transferred onto PVDF membranes
(Immobilon-P; Millipore) for Western blotting. Membranes were blotted with A2-specific antibodies, which were generated against the dominant epitope of the wtA2 protein and secreted from the C9 hybridoma cell line (Zhang et al., 1996), diluted 1:20000 in PBS +1\% Tween 20 (Fisher) containing 5\% non-fat dried milk. Anti-mouse secondary antibodies against total IgG, conjugated to horseradish peroxidase (HRP; Sigma), were used at a dilution of 1:20000 in PBS $+1 \%$ Tween 20 with $5 \%$ non-fat dried milk. Membranes were detected using Immobilon Western Chemiluminescence HRP Substrate (Millipore) and visualized on radiographic film or using the VersaDoc Molecular Imager (Bio-Rad) with QuantityOne software (Bio-Rad).

\section{Preparation of bacteria for whole-cell ELISA or immunizations.} Following nisin induction as described above, Lactococcus lactis cultures were washed twice in PBS, and resuspended in PBS $+25 \%$ glycerol at $1 /$ 25 th of the starting volume. Bacterial cultures were aliquotted and stored at $-80{ }^{\circ} \mathrm{C}$. The bacterial concentration of one aliquot was determined, and the dilution factor was calculated for the remaining aliquots to obtain the necessary concentration. First, an aliquot of frozen bacteria was allowed to thaw on ice and centrifuged $(3000 \mathrm{~g}$, $10 \mathrm{~min}, 4^{\circ} \mathrm{C}$ ), the supernatant was removed and the bacterial cells were resuspended in the same volume of PBS. Serial dilutions and c.f.u. counts were performed to determine the bacterial concentration and to calculate the dilution factor to obtain $\sim 10^{10}$ c.f.u. $\mathrm{ml}^{-1}$. This dilution factor was confirmed by thawing another aliquot, which was centrifuged, resuspended in PBS and quantified by serial dilutions and c.f.u. counts. Finally, when live A2-expressing Lactococcus lactis was needed for whole-cell ELISA or mouse immunizations, a frozen aliquot was thawed on ice, centrifuged as above and resuspended in PBS to obtain the necessary bacterial concentration, which was again confirmed by serial dilutions and c.f.u. counts. For each batch of Lactococcus lactis prepared, correct A2 expression was also confirmed by immunoblotting and whole-cell ELISA. 
Table 2. Bacterial strains and plasmids used in this study

\begin{tabular}{|c|c|c|}
\hline Name & Description & Reference/supplier \\
\hline \multicolumn{3}{|l|}{ Bacterial strains } \\
\hline E. coli $\mathrm{DH} 5 \alpha$ & Standard laboratory strain used for DNA cloning and amplification & Invitrogen \\
\hline E. coli BL21(DE3) & Contains the T7 promoter under an IPTG-inducible promoter & Novagen \\
\hline Lactococcus lactis NZ9000 & $\begin{array}{l}\text { A plasmid-free derivative of the dairy starter strain NCDO71 } \\
\text { that is suitable for use as a live vaccine vector }\end{array}$ & Kuipers et al. (1998) \\
\hline \multicolumn{3}{|l|}{ Plasmids } \\
\hline pDL278 & E. coli/Lactococcus lactis shuttle plasmid & LeBlanc et al. (1992) \\
\hline pDL-P $\mathrm{P}_{\text {nis }}$ & The nisin-inducible promoter $\left(\mathrm{P}_{n i s A}\right)$ added to pDL278 & This work \\
\hline pDL- $\mathrm{P}_{n i s A} \mathrm{~B}$ & $\begin{array}{l}\text { A unique } B s g I \text { restriction site added downstream of the } \\
\text { promoter in pDL- } \mathrm{P}_{n i s A}\end{array}$ & This work \\
\hline pDL-P ${ }_{n i s A}-$ cytoA2 $2_{1}$ & $\begin{array}{l}\text { One } 10 \text { aa repeat of the } \mathrm{A} 2 \text { protein added to } \mathrm{pDL}-\mathrm{P}_{\text {nis }} \mathrm{B} \\
\text { downstream of the promoter }\end{array}$ & This work \\
\hline pDL-P ${ }_{n i s A}-$ cytoA2 $2_{3}$ & Two 10 aa repeats of the A2 protein added to pDL- $\mathrm{P}_{n i s A}-\mathrm{cytoA} 2_{1}$ & This work \\
\hline pDL-P ${ }_{\text {nisA }}-$ cytoA $2_{10}$ & $\begin{array}{l}\text { Consecutive additions of doublets of the } \mathrm{A} 2 \text { repeat added to } \\
\text { pDL- } \mathrm{P}_{\text {nis }}-\text { cytoA2 }{ }_{3} \text {; the largest stable construct produced contained } \\
\text { ten copies of the } \mathrm{A} 2 \text { repeat downstream of the } \mathrm{P}_{\text {nisA }} \text { promoter. }\end{array}$ & This work \\
\hline $\mathrm{pDL}-\mathrm{P}_{n i s A}-\mathrm{sec} \mathrm{2} 2_{10}$ & $\begin{array}{l}\text { The Usp } 45 \text { secretion signal added between the promoter and } \\
\mathrm{A} 2_{10} \text { gene in pDL- } \mathrm{P}_{\text {nisA }} \text {-cytoA } 2_{10}\end{array}$ & This work \\
\hline pDL-P ${ }_{n i s A}-$ cytoA2 ${ }_{10} \mathrm{~N}$ & A unique NheI restriction site added to the $3^{\prime}$ end of the $\mathrm{A} 2_{10}$ gene & \\
\hline pDL-P ${ }_{n i s A^{-c w a A}} 2_{10}$ & $\begin{array}{l}\text { The Usp } 45 \text { secretion signal added at the } 5^{\prime} \text { end and the cell-wall } \\
\text { anchoring (cwa) domain of the M6 protein of Streptococcus pyogenes } \\
\text { added to the } 3^{\prime} \text { end of the } \mathrm{A} 22_{10} \text { gene in pDL- } \mathrm{P}_{\text {nis }} \mathrm{A}^{- \text {cyto }} 2_{10} \mathrm{~N}\end{array}$ & This work \\
\hline pET-16b & Plasmid to create $\mathrm{N}$-terminally His-tagged proteins in E. coli & Novagen \\
\hline pET-A2 10 & $\begin{array}{l}\text { The } \mathrm{A} 2_{10} \text { gene from pDL- } \mathrm{P}_{\text {nis }} \text {-cytoA } 2_{10} \text { added to pET- } 16 \mathrm{~b} \text { to } \\
\text { create a His-tagged version of } \mathrm{A} 2_{10}\end{array}$ & This work \\
\hline pET-wtA2 & His-tagged version of the wild-type A2 from Leishmania donovani & Charest \& Matlashewski (1994) \\
\hline
\end{tabular}

Whole-cell ELISA. A whole-cell ELISA protocol was developed from previously described methods (Avall-Jääskeläinen et al., 2002; Tsang et al., 1995). Live A2-expressing Lactococcus lactis was prepared as above; however, the medium supernatant was retained after nisin induction and stored at $-20{ }^{\circ} \mathrm{C}$. Live bacteria were diluted in PBS to $10^{9}$ c.f.u. $\mathrm{ml}^{-1}$ and a portion was used to prepare heat-killed Lactococcus lactis by incubating in boiling water for $1 \mathrm{~h}$. ELISA plates were coated with live and heat-killed bacteria $\left(10^{8}\right.$ bacteria in $100 \mu \mathrm{l}$ per well) and supernatant for each Lactococcus lactis strain in triplicate at $4{ }^{\circ} \mathrm{C}$ overnight. Before and after every step, wells were washed with PBS $+0.5 \%$ Tween 20. Wells were blocked with PBS $+1 \%$ BSA (blocking solution) for $1 \mathrm{~h}$, and A2-specific antibodies (C9 cell line supernatant, diluted $1: 2000$ in blocking solution) was allowed to bind for $2 \mathrm{~h}$. Finally, wells were incubated with HRP-conjugated antimouse IgG secondary antibody (diluted $1: 2000$ in blocking solution; Sigma) for $1 \mathrm{~h}$. The presence of A2 protein was detected by the addition of the substrate 2,2'-azino-bis(3-ethylbenzthiazoline-6sulfonic acid) (ABTS; Sigma) and plates were read at $405 \mathrm{~nm}$. Data are presented as the fold increase compared with Lactococcus lactis containing the empty vector (Lactococcus lactis/vector) for each cellular localization of the protein.

Intracellular growth assay. Experiments were performed using a protocol modified slightly from previously described methods (BaheyEl-Din et al., 2008). In brief, $0.5 \times 10^{6} \mathrm{~J} 774$ macrophage cells were plated in $1 \mathrm{ml}$ RPMI 1640 (Gibco) containing $10 \%$ fetal bovine serum (FBS; Wisent) in six-well tissue culture plates (Becton Dickinson) and incubated at $37{ }^{\circ} \mathrm{C}$ with $5 \% \mathrm{CO}_{2}$ overnight. Cells were washed with $5 \mathrm{ml}$ medium and co-incubated with $10^{8}$ Lactococcus lactis for $1 \mathrm{~h}$. Cells were then washed twice and incubated in RPMI 1640 containing $20 \mu \mathrm{g}$ gentamicin (Gibco) $\mathrm{ml}^{-1}$ for an additional $1 \mathrm{~h}$. After a final wash, cells were lysed in $2 \mathrm{ml}$ cold, sterile PBS $+0.1 \%$ Triton X-100 (Fisher) and serial dilutions were plated on GM17 agar plates with or without antibiotic (spectinomycin). Alternatively, a second set of cells was incubated for an additional $6 \mathrm{~h}$ after replacement of the gentamicincontaining medium with fresh medium.

Immunizations. Six-week-old female BALB/c mice were purchased from Charles River Laboratories. Groups of mice were immunized subcutaneously on days 0,14 and 28 with $\sim 2 \times 10^{9}$ c.f.u. live Lactococcus lactis expressing A2 in each of the three subcellular localizations (Lactococcus lactis/cytoA2, Lactococcus lactis/secA2 or Lactococcus lactis/cwaA2), Lactococcus lactis containing the empty plasmid vector (Lactococcus lactis/vector) or PBS only. All immunizations were performed with a total volume of $200 \mu \mathrm{l}$. Blood was collected from the lateral saphenous vein on days 7, 21, 35, 56 and 70 after the first immunization. Serum samples were stored at $-20{ }^{\circ} \mathrm{C}$ until analysis. Mice were challenged with Leishmania donovani infection on day 42 .

All procedures were in accordance with the guidelines of the Canadian Council on Animal Care, as approved by the Animal Care Committee of McGill University.

Serum antibody analyses. Reciprocal end-point titres of A2specific $\operatorname{IgG}, \operatorname{IgG}_{1}$ and $\operatorname{IgG}_{2 \mathrm{a}}$ antibodies were determined in serum samples from individual mice. Briefly, ELISA plates were coated with His-A2 purified protein $\left(2.5 \mu \mathrm{g} \mathrm{ml} \mathrm{m}^{-1} ; 50 \mu \mathrm{l}\right.$ per well $)$ at $4{ }^{\circ} \mathrm{C}$ overnight. Before and after every subsequent step, wells were washed with PBS $+0.5 \%$ Tween 20. Twofold serial dilutions of serum samples were prepared, and added to wells at a starting dilution of $1: 50$ in PBS $+2.5 \%$ FBS. HRP-conjugated anti-mouse antibodies against total IgG, or goat anti-mouse $\operatorname{IgG}_{1}$ or $\operatorname{IgG}_{2 \mathrm{a}}$ followed by HRPconjugated anti-goat secondary antibodies (Sigma), were used. 
Finally, plates were detected using ABTS substrate and read at $405 \mathrm{~nm}$. The end-point was determined as the highest serum dilution to reach the same absorbance reading as naive pre-immune sera ( $1: 50$ dilutions) plus $2 \mathrm{SD}$.

Western blotting analysis was performed to confirm the specificity of the ELISA results. Pooled serum samples from each mouse immunization group were immunoblotted $(1: 100$ dilutions in PBS $+1 \%$ BSA) against $0.5 \mu$ g His-A2 purified protein, which was resolved by $18 \%$ SDS-PAGE and transferred to PVDF membrane. Total IgG, IgG 1 or $\operatorname{IgG}_{2 a}$ A2-specific antibodies in serum were detected using the secondary antibodies as above. Detection was carried out as described for immunoblotting.

Parasite challenge and soluble Leishmania antigen (SLA) preparation. Leishmania donovani strain 1S2D expressing episomal luciferase (Roy et al., 2000) was maintained at $25^{\circ} \mathrm{C}$ in SDM medium supplemented with $10 \%$ FBS, as described previously (Abu-Dayyeh et al., 2008). Mice were challenged with Leishmania infection 2 weeks after the last immunization (day 42).

Mice were challenged with $1 \times 10^{7}$ (low dose) or $4 \times 10^{7}$ (high dose) late-stationary-phase Leishmania donovani promastigotes in $100 \mu \mathrm{lPS}$ injected in the tail vein. At 4 weeks post-infection (p.i.), mice were sacrificed and Leishman-Donovan units (LDU) were calculated as described previously (Roy et al., 2000). Briefly, microscope slides of liver impression smears were prepared and stained with Diff-Quick solution (Dade Behring). The LDU was calculated as the number of amastigotes counted per 1000 nucleated cells multiplied by the liver weight (mg). The results shown represent five to ten mice per group for the low-dose challenge and ten mice per group for the high-dose challenge.

To prepare SLA, late-stationary-phase Leishmania donovani promastigotes were first resuspended in sterile PBS to a concentration of $\sim 10^{8}$ parasites $\mathrm{ml}^{-1}$. Parasites were lysed by five cycles of freezethawing, then centrifuged in a microcentrifuge $\left(14000\right.$ r.p.m., $4{ }^{\circ} \mathrm{C}$, $15 \mathrm{~min}$ ). The supernatant (SLA) was collected and protein concentration was determined by a Bradford assay (Bio-Rad).

Ex vivo stimulation of splenocytes. Spleens were excised from mice immunized and challenged with Leishmania donovani at 4 weeks p.i. Single-cell suspensions of splenocytes were prepared and adjusted to $2 \times 10^{6}$ cells $\mathrm{ml}^{-1}$ in RPMI 1640 supplemented with $10 \% \mathrm{FBS}$, $1 \mathrm{mM}$ penicillin/streptomycin and $0.5 \mathrm{mM} \quad \beta$-mercaptoethanol. Splenocytes were plated in 24 -well plates at $2 \times 10^{6}$ cells in a total of $2 \mathrm{ml}$. Cells were stimulated with SLA prepared from Leishmania donovani at $50 \mu \mathrm{g} \mathrm{ml}^{-1}$ for 3 days. Cell culture supernatants were collected and stored at $-80{ }^{\circ} \mathrm{C}$ until quantification of cytokines by ELISA. The concentrations of gamma interferon (IFN- $\gamma$ ), interleukin 2 (IL-2) and IL-10 were determined using ELISA Ready-SET-Go! Cytokine kits according to manufacturer's protocols (eBiosciences). The results shown represent five mice per group.

Statistical analysis. Statistical significance between groups was determined using the analysis of variance function of the StatView program, version 5.0 (SAS Institute).

\section{RESULTS}

\section{Generation of a truncated A2 protein for expression in bacteria}

To enhance expression of a Leishmania protein in Lactococcus lactis, we engineered a codon-optimized version of the gene encoding the A2 antigen. Heterologous gene expression in Lactococcus lactis is enhanced by the replacement of rare bacterial codons (Fuglsang, 2003). Proteins of the A2 family from Leishmania donovani consist of an $\mathrm{N}$-terminal leader sequence followed by a variable number of tandem repeats of a 10 aa dominant epitope followed by a 7 aa C-terminal region (Charest \& Matlashewski, 1994; Zhang et al., 2003). In comparison, the A2 protein generated for expression in bacteria contained ten copies of the 10 aa repeat (Fig. 1a). The His-tagged purified bacterial A2 protein separated by $18 \%$ SDS-PAGE had a size of $14 \mathrm{kDa}$, which corresponded to the molecular size of this protein, whilst A2 expressed from Leishmania donovani cDNA in E. coli was $54 \mathrm{kDa}$ (Fig. 1b) (Charest \& Matlashewski, 1994). The codon-optimized A2 protein was also recognized by A2-specific antibodies (Zhang et al., 1996) when analysed by Western blotting, similar to the wild-type A2 from Leishmania donovani expressed in E. coli (Fig. 1c).

\section{Expression and localization of A2 in three different subcellular compartments of Lactococcus lactis}

A2 expression in Lactococcus lactis was directed to different subcellular localizations to determine which presentation strategy stimulated the highest level of protection against leishmaniasis. As described in Methods, A2 was expressed in the cytoplasm (Lactococcus lactis/cytoA2), secreted from the bacterial cell (Lactococcus lactis/secA2) and anchored to the cell wall (Lactococcus lactis/cwaA2) (Fig. 1d).

To confirm the expression levels and localization of A2 in Lactococcus lactis following nisin induction, Western blot analyses and a whole-cell ELISA were performed on the three strains of Lactococcus lactis. As shown in Fig. 1(e), following nisin induction, A2 protein was detectable in all strains of A2-expressing Lactococcus lactis but was absent in the negative-control strain (Lactococcus lactis/vector). Furthermore, by cell fractionation and Western blot analysis, the three strains of A2-expressing Lactococcus lactis exhibited bands corresponding to A2 in the anticipated fractions (Fig. 1f). A2 protein directed to the cytoplasm (cytoA2, 105 aa, $12 \mathrm{kDa}$ ) was detected primarily in the cell-wall fraction (Fig. 1f), but at longer exposures of the Western blot it was also detected in the protoplast fraction. Previous studies have shown that, with this cell fractionation protocol, the ionic charge of proteins and the salt concentration of the growth medium can lead to cytoplasmic proteins appearing in the cell-wall fraction (Dieye et al., 2001). The localization of cytoA2 was confirmed by whole-cell ELISA (Fig. 1g). In comparison with Lactococcus lactis/vector, cytoA2 was detected mainly in the cell lysate, minimally on the surface of intact cells and not in the culture supernatant. Therefore, Lactococcus lactis/cytoA2 correctly expressed cytoA2 in the cytoplasm. Similar analyses confirmed the expression and correct localization of secA2 and cwaA2 (Fig. 1f, g). The secA2 protein was detectable in all cell fractions; this was expected, as the protein would first be expressed in the cytoplasm with the secretion signal (146 aa, $15 \mathrm{kDa})$, 
which would then be cleaved during processing to direct the protein into the culture supernatant (12 kDa) (Fig. 1f). Whole-cell ELISA results confirmed that secA2 was detectable on the cell surface before processing of the secretion signal but was found mainly in the culture supernatant (Fig. 1g). Finally, with the addition of the cwa domain, the larger size of cwaA2 was seen as expected in the protoplast and cell-wall fractions on the Western blot (304 aa, $34 \mathrm{kDa}$ ) (Fig. 1f). Smaller bands of cwaA2 were also detected in the culture supernatant, which may correspond to proteins that were located initially on the cell surface but were sloughed off during renewal of the cell wall. Corresponding with the Western blot data, high levels of cwaA2 were detected on the cell surface of this strain in comparison with Lactococcus lactis/vector, as well as in the cell lysate and the culture supernatant (Fig. 1g).

\section{Intracellular fate of Lactococcus lactis in the J774 macrophage cell line}

To assess infectivity, bacterial fate and plasmid stability in J774 cells, Lactococcus lactis was incubated with macrophages for 2 or 8 h. Cells were then lysed and bacterial c.f.u. counts were determined. At both time points, there was no detectable difference in the c.f.u. counts between plasmidfree Lactococcus lactis NZ9000 and Lactococcus lactis harbouring the different constructs (empty vector, cytoA2, secA2 and cwaA2) (data not shown). This indicated that the higher metabolic burden of protein expression did not affect the infectivity of Lactococcus lactis in vitro. However, the number of live Lactococcus lactis recovered from macrophages decreased two- to fourfold following the additional $6 \mathrm{~h}$ period, which suggests that Lactococcus lactis bacteria are incapable of long-term survival within macrophages (data not shown; Bahey-El-Din et al., 2008). Finally, we also compared c.f.u. counts of the different strains plated with or without antibiotic to assess plasmid stability. At both time points, we were unable to detect any differences in c.f.u. counts between bacteria grown on plates with or without antibiotic (data not shown), indicating that all plasmids were well maintained within the Lactococcus lactis cells.

\section{Antigen-specific humoral responses following administration of A2-expressing Lactococcus lactis live vaccines}

Mice were immunized by subcutaneous injections of live bacteria at 2-week intervals for a total of three immunizations. Alternatively, mice were immunized with PBS only or Lactococcus lactis containing the empty plasmid vector without antigen expression (Lactococcus lactis/vector) as negative controls. To determine whether the antigen in the context of Lactococcus lactis live vaccines was recognized by the immune system, the strains of A2-expressing Lactococcus lactis were evaluated for their ability to generate antigenspecific antibodies. Serum samples were collected from individual mice on alternate weeks from the weeks in which mice were immunized.
Interestingly, only expressed A2 anchored to the cell wall of Lactococcus lactis (not cytoplasmic or secreted expression) was able to induce high levels of A2-specific IgG antibodies in serum (Fig. 2a). In mice that were immunized with Lactococcus lactis/cwaA2, the end-point A2 titre was as high as $10^{4}$ (Fig. 2a). The specificity of ELISA results was also confirmed by Western blot; only mice immunized with Lactococcus lactis/cwaA2 exhibited noticeable production of A2-specific antibodies (Fig. 2b).

The isotype of the antigen-specific antibodies produced is an indicator of the type of immune response generated. The induction of a T-helper 1 (Th1)-type immune response results in an isotype switch to $\operatorname{IgG}_{2 \mathrm{a}}$, whilst a Th2type immune response promotes production of $\mathrm{IgG}_{1}$ (Stavnezer, 1996). Immunization with Lactococcus lactis/ cwaA2 induced A2-specific antibodies of both isotypes, $\mathrm{IgG}_{1}$ and $\mathrm{IgG}_{2 \mathrm{a}}$, which suggested that both Th1 and Th2 immune responses were induced (Fig. 2c). However, the ratio of $\operatorname{IgG} \mathrm{G}_{1}: \operatorname{IgG}_{2 \mathrm{a}}$ antibodies generated following immunization with Lactococcus lactis/cwaA2 was 2.42, suggesting that there was predominantly a Th2-type response against the A2 antigen in the immunized mice when $\mathrm{A} 2$ was delivered by Lactococcus lactis.

\section{Evaluation of A2-expressing Lactococcus lactis live vaccines against Leishmania donovani challenge}

Next, we assessed the efficacy of A2-expressing Lactococcus lactis live vaccines against Leishmania donovani infection. The A2 antigen was originally isolated from this strain of Leishmania, and immunization with purified A2 protein has been shown previously to protect mice against Leishmania donovani infection (Charest \& Matlashewski, 1994; Ghosh et al., 2001b). Mice were challenged with a low or high dose of Leishmania donovani promastigotes injected intravenously 2 weeks after the final immunization (day 42), and disease was allowed to progress for 4 weeks.

Following challenge with Leishmania donovani infection, mice in the negative-control groups (immunized with PBS and Lactococcus lactis/vector) demonstrated comparable levels of parasitaemia, as determined by the LDU (Fig. 3). LDU values of both groups of control mice that received the low dose of parasites reached levels above $8000 \mathrm{LDU}$ (Fig. 3a), whilst for the high-dose challenge, the control mice reached $\sim 80000$ LDU (Fig. 3b). Following low-dose challenge, mice that were immunized with Lactococcus lactis/cytoA2 and Lactococcus lactis/cwaA2 demonstrated a reduction in LDU (Fig. 3a). Interestingly, as seen with the high-dose parasite challenge, mice that were immunized with Lactococcus lactis/cytoA2 also exhibited the lowest LDU in comparison with control mice (Fig. 3a, b). Immunization with Lactococcus lactis/cytoA2 resulted in reductions of approximately 50 and $40 \%$ in LDU in comparison with control mice after low- and highdose challenge with Leishmania donovani, respectively. However, this reduction in LDU by immunization 


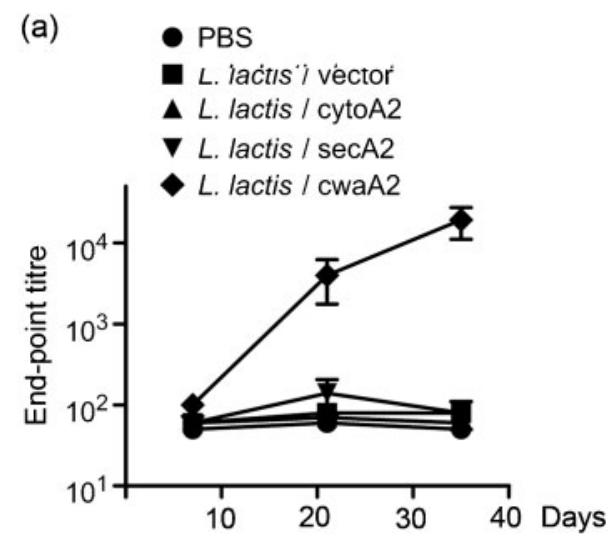

(b)

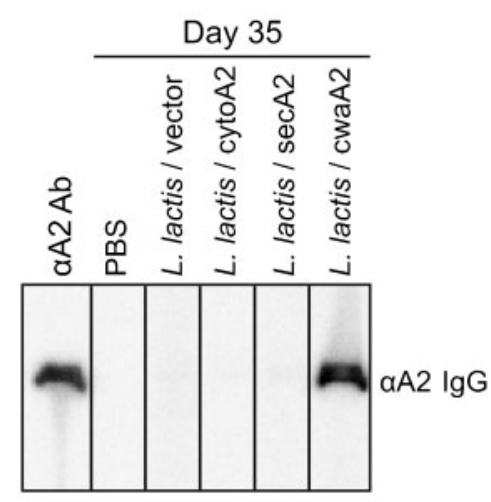

(c)

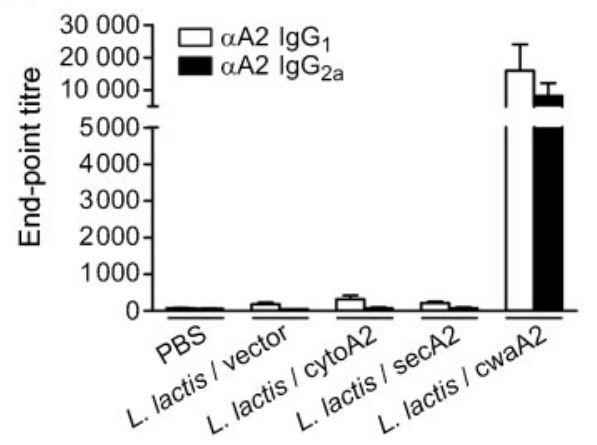

Fig. 2. Antigen-specific humoral responses following administration of A2-expressing Lactococcus lactis live vaccines. Detection of anti-A2 total $\lg G, \lg _{1}$ and $\lg _{2 a}$ antibodies in the serum of mice immunized subcutaneously with $A 2$-expressing Lactococcus lactis strains. (a) End-point anti-A2 total $\lg G$ antibody titres measured by ELISA of serum samples from individual mice taken on days 7, 21 and 35. Mice were immunized on days 0, 14 and 28.

(b) Western blot analysis of pooled serum samples taken on day 35 for each immunization group. Each pooled sample was immunoblotted against $0.5 \mu \mathrm{g}$ His-A2 on strips of PVDF membrane. $\alpha \mathrm{A} 2 \mathrm{Ab}$, control anti-A2 antibody. (c) End-point anti-A2 total $\lg _{1}$ and $\lg _{2 a}$ antibody titres measured by ELISA of serum samples from individual mice taken on day 35. Data are presented as means \pm SEM of five mice per group and are representative of two independent experiments. (a)

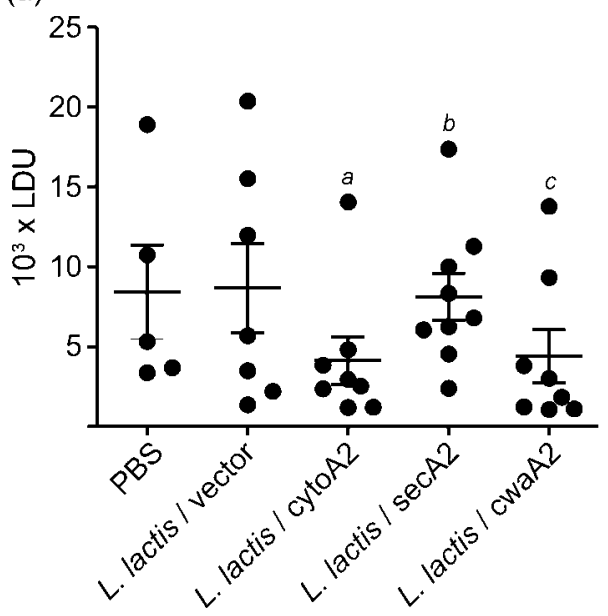

(b)



Fig. 3. Protection from A2-expressing Lactococcus lactis live vaccines against Leishmania donovani challenge. Mice immunized subcutaneously with A2-expressing Lactococcus lactis live vaccines were challenged with $1 \times 10^{7}$ (low dose) (a) or $4 \times 10^{7}$ (high dose) (b) of Leishmania donovani parasites injected intravenously. Liver parasitaemia was determined at 4 weeks p.i. by calculating LDU values. Data are presented as means \pm SEM of five to ten mice per group for the low-dose challenge and ten mice per group for the high-dose challenge. Each dot represents the results for one mouse. $P$ values are given compared with PBS and Lactococcus lactis/vector, respectively: $a, P=0.1720$ and $P=0.1128 ; b$, $P=0.9221$ and $P=0.8405 ; c, P=0.2008$ and $P=0.1358 ; d$, $P=0.0590$ and $P=0.0880 ; e, P=0.4377$ and $P=0.5594 ; f$, $P=0.3435$ and $P=0.4499$.

with Lactococcus lactis/cytoA2 did not reach statistical significance.

\section{Antigen-specific immune responses of A2- expressing Lactococcus lactis live vaccines after Leishmania donovani challenge}

Blood samples from individual mice were collected at 2 and 4 weeks after mice were challenged with Leishmania 
donovani infection (at days 56 and 70 following the initial immunization). Similar to the results before challenge, only mice that were immunized with Lactococcus lactis/cwaA2 induced high levels of A2-specific antibodies (Fig. 4a), which reached titres above $10^{5}$. Again, the specificity of the ELISA results was confirmed by Western blotting and demonstrated that A2-specific antibodies were indeed only produced in mice immunized with Lactococcus lactis/ cwaA2 (Fig. 4b). Furthermore, mice that received the Lactococcus lactis/cwaA2 live vaccine produced antigenspecific antibodies of both $\operatorname{IgG}_{1}$ and $\operatorname{IgG}_{2 a}$ isotypes, indicating that there was an induction of both Th1- and Th2-type immune responses (Fig. 4c). However, the ratio of A2-specific $\operatorname{IgG}_{1}: \operatorname{IgG}_{2 a}$ antibodies was 4.67 , which was higher than that observed for the serum samples taken before mice were challenge with Leishmania infection, suggesting that a stronger Th2-type immune response was induced.

To clarify further the type of immune response produced, at the end of the low-dose Leishmania donovani challenge (4 weeks p.i.), splenocytes from individual mice were isolated and then restimulated with SLA. Splenocytes were restimulated with SLA to investigate the immune response against the entire parasite. Cytokines from tissue culture supernatants were quantified by ELISA. Interestingly, following restimulation with SLA, splenocytes from all animals produced IFN $-\gamma$ at levels higher than unstimulated samples (Fig. 5a). In addition, mice that were immunized with Lactococcus lactis expressing cytoA2 and cwaA2 live vaccines expressed even higher levels of IFN- $\gamma$. Following the same trend as seen with IFN- $\gamma$, splenocytes from mice that received Lactococcus lactis/cytoA2 and Lactococcus lactis/ cwaA2 induced significant levels of IL-10 following SLA restimulation in comparison with PBS (Fig. 5b). However, in comparison with Lactococcus lactis/vector, the levels of IL-10 induced by Lactococcus lactis/cytoA2 and Lactococcus lactis/cwaA2 were not significant. In contrast, splenocytes from mice that received Lactococcus lactis live vaccines all induced low levels of IL- 4 following restimulation with SLA; however, these were near or below the limit of detection of the assay (data not shown). Finally, both unstimulated and SLA-stimulated splenocytes from all mice produced detectable levels of IL-2 (Fig. 5c). Again, the same trend was observed, in that splenocytes from mice that received Lactococcus lactis/cytoA2 and Lactococcus lactis/cwaA2 appeared to induce slightly higher levels of IL-2.

\section{DISCUSSION}

The objective of this study was to compare different methods of antigen expression and delivery by live Lactococcus lactis, and to test Lactococcus lactis-based vaccines for protection against Leishmania donovani infection in $\mathrm{BALB} / \mathrm{c}$ mice. We generated a truncated $\mathrm{A} 2$ protein encoded by a synthetic gene that was optimized for expression in bacteria. For our synthetic A2 gene, all codons were exchanged for their most common counterparts in (a)

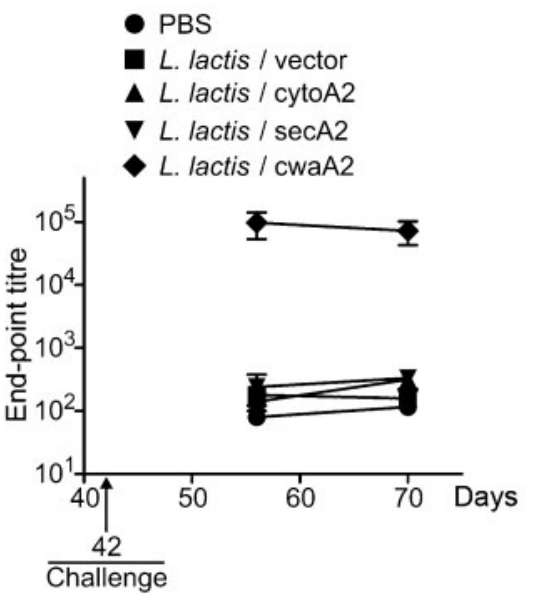

(b)

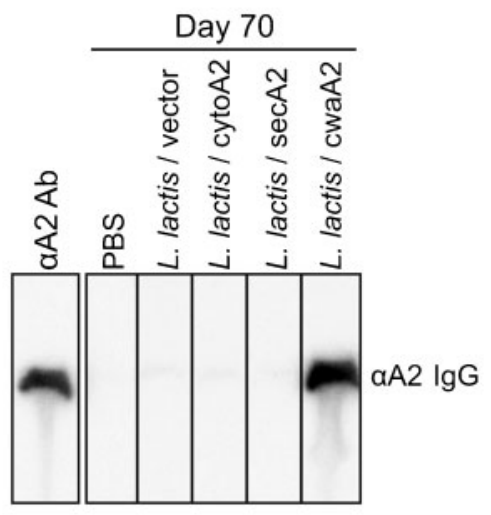

(c)

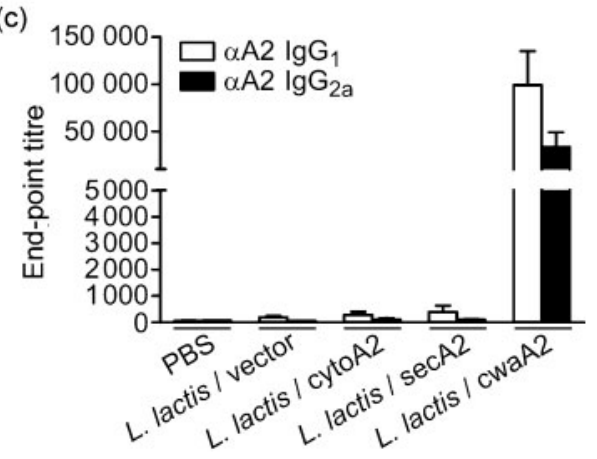

Fig. 4. Antigen-specific humoral responses following challenge with Leishmania infection, and detection of anti-A2 total $\lg G, \lg \mathrm{G}_{1}$ and $\lg G_{2 a}$ antibodies in serum of mice following immunization with A2-expressing Lactococcus lactis live vaccines and challenge with Leishmania donovani infection. (a) End-point anti-A2 total IgG antibody titres measured by ELISA of serum samples from individual mice taken on days 56 and 70 after the initial immunization. (b) Western blot analysis of pooled serum samples taken on day 70 for each immunization group. Each pooled sample was immunoblotted against $0.5 \mu \mathrm{g}$ His-A2 on strips of PVDF membrane. $\alpha \mathrm{A} 2 \mathrm{Ab}$, control anti-A2 antibody. (c) End-point antiA2 total $\lg _{1}$ and $\lg G_{2 a}$ antibody titres measured by ELISA of serum samples from individual mice taken on day 70 . Data are presented as the means \pm SEM of six mice per group and are representative of two independent experiments. 


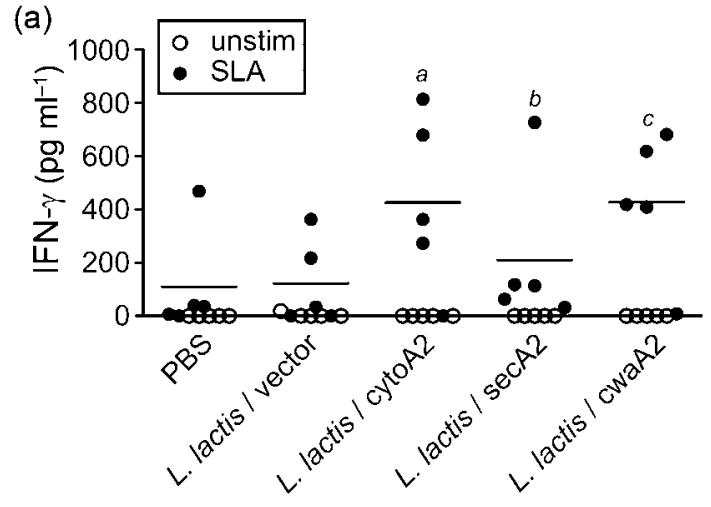

(b)

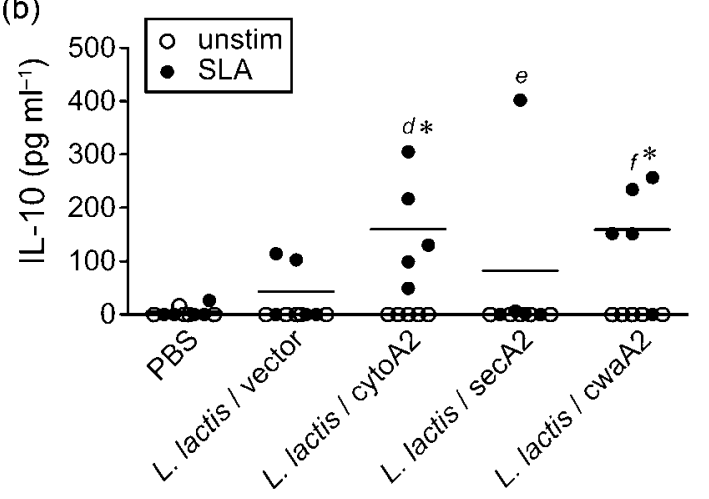

(c)

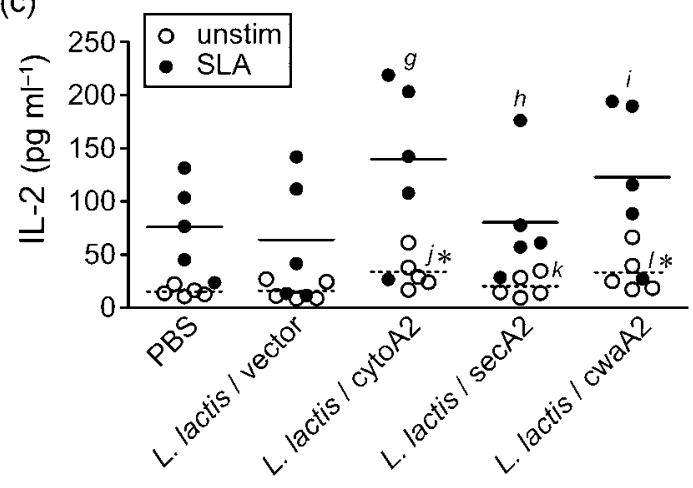

Fig. 5. Splenocyte cytokine responses following challenge with Leishmania donovani infection. Splenocytes of mice immunized subcutaneously with A2-expressing Lactococcus lactis live vaccines and challenged with low-dose Leishmania donovani parasites were restimulated ex vivo with SLA. The concentration of cytokines IFN- $\gamma$ (a), IL-10 (b) and IL-2 (c) in splenocyte culture supernatants was determined after 3 days of stimulation. Data are presented as means \pm SEM of five mice per group. $P$ values for the SLA-stimulated samples are given compared with PBS and Lactococcus lactis/vector, respectively: $a, P=0.0646$ and $P=0.0752 ; b, P=0.5390$ and $P=0.5913 ; c, P=0.0636$ and $P=0.0741 ; d, P=0.0316$ and $P=0.0966 ; e, P=0.2652$ and $P=0.5690 ; f, P=0.0327$ and $P=0.0996 ; g, P=0.1235$ and $P=0.0705 ; h, P=0.9193$ and $P=0.6893 ; i, P=0.2507$ and $P=0.1529$. $P$ values for the unstimulated (IL-2) samples are given compared with PBS and Lactococcus lactis/vector, respectively: $j$, $P=0.0429$ and $P=0.0525 ; k, P=0.5667$ and $P=0.6377$; and $I$, $P=0.0471$ and $P=0.0576$. ${ }^{*}, P<0.05$ (see above for details).
Lactococcus lactis. Originally, eight of the ten amino acids of the $\mathrm{A} 2$ repeat were coded by the most rarely used codon in Lactococcus lactis. Bioinformatic analysis of Lactococcus lactis gene expression has shown that highly expressed genes have a different codon bias in comparison with seldom-expressed genes (Fuglsang, 2003); therefore, codon optimization was predicted to enhance expression of our synthetic A2 gene. We engineered constructs that expressed A2 in the cytoplasm, secreted it outside the cell and anchored it to the cell wall of Lactococcus lactis. These general molecular approaches will be useful for generating future Lactococcus lactis live vaccines using different Leishmania antigens alone or in combination with $\mathrm{A} 2$.

According to our Western blot and whole-cell ELISA analyses, all the A2-expressing strains of Lactococcus lactis expressed the antigen correctly in the expected compartment. However, we also detected cwaA2 in the supernatant of this strain. This is unlike previous studies, where expressed antigens that were anchored to the cell wall of Lactococcus lactis did not appear in the supernatant according to Western blot results (Bermúdez-Humarán et al., 2004; Medina et al., 2008; Scavone et al., 2007). In contrast, when the L7/L12 antigen of Brucella abortus was similarly directed to expression on the cell wall of Lactococcus lactis, it was also detected by Western blot in the supernatant (Ribeiro et al., 2002). We hypothesize that this is a result of the stability of the antigen in the growth medium, as there was no correlation with antigen size leading to surface degradation. This difference may also be a result of the conditions used for protein induction. Previous studies using the nisin-inducible promoter induced antigen expression for 1-2 h. However, for our studies, we induced the expression of A2 for $3 \mathrm{~h}$. We found that a longer induction time was able to produce more protein and led to more accumulated antigen within each bacterial cell before its use as a live vaccine. However, as Lactococcus lactis produces lactic acid as it grows, a longer growth period would lead to a more acidic medium, which may also cause increased protein degradation on the cell surface. Future studies to minimize this effect could use the htrA-NZ9000 strain, which may reduce protein proteolysis on the surface of Lactococcus lactis (Miyoshi et al., 2002). HtrA is a surface protease of Lactococcus lactis, and inactivation of this protein was shown to reduce degradation of heterologous proteins expressed on the surface of Lactococcus lactis.

We tested the efficacy of our A2-expressing Lactococcus lactis live vaccines by immunizing mice subcutaneously and then challenging them with systemic infection with Leishmania donovani. We chose the subcutaneous route of administration because oral administration would most probably provide humoral mucosal immune responses, which should be non-protective against Leishmania infection. In addition, it was previously shown that parenteral injection of Lactococcus lactis live vaccine induced higher levels of antigen-specific immune responses in comparison with intragastric and intranasal vaccine 
administration (Robinson et al., 2004). We found that subcutaneous injection of $\sim 2 \times 10^{9}$ live bacteria in mice was well tolerated; however, occasionally there was formation of skin ulcerations at the site of injection, which were nevertheless resorbed during subsequent weeks. This is consistent with another study that safely administered $10^{10}$ live Lactococcus lactis to mice by subcutaneous injection (Buccato et al., 2006).

Interestingly, immunization with only the cell-wall-anchored version of A2 in Lactococcus lactis (Lactococcus lactis/cwaA2) generated high levels of antibodies before challenge. Similar to our results, expression of the E7 antigen of human papilloma virus anchored to the cell wall also induced the highest levels of antigen-specific cellular immune responses following immunization of mice (Bermúdez-Humarán et al., 2004). The undetectable levels of antibodies generated by the Lactococcus lactis strains expressing cytoplasmic and secreted A2 could have resulted from the antigen being mainly intracellular and sequestered from the immune system. In addition, secreted A2, which is mostly present in the bacterial culture supernatant, was probably washed away during preparation of the live bacteria prior to immunization. These results clearly demonstrate that the subcellular location of antigen expression has a critical influence on the immune response generated.

We tested the efficacy of our A2-expressing Lactococcus lactis live vaccines against visceral Leishmania donovani infection. Mice that were immunized with PBS and Lactococcus lactis/ vector exhibited similar levels of liver parasitaemia (LDU). Notably, mice immunized with Lactococcus lactis/cytoA2 demonstrated the highest reduction in LDU, which was seen at both low- and high-dose parasite challenges, whilst immunization with Lactococcus lactis/cwaA2 also led to a reduction in LDU following only the low-dose challenge.

Similar to before challenge, only mice that were immunized with Lactococcus lactis/cwaA2 produced significant levels of A2-specific antibodies after challenge. It was also noteworthy that, although Lactococcus lactis/cwaA2 induced high levels of antigen-specific antibodies, it did not result in a stronger reduction in parasitaemia than Lactococcus lactis/ cytoA2, as seen after high-dose infection with Leishmania donovani. Moreover, investigation of antigen-specific antibody isotypes $\left(\operatorname{IgG}_{1}\right.$ and $\operatorname{IgG}_{2 \mathrm{a}}$ ) indicated that, following parasite challenge, there was further development of a Th2 immune response. This is similar to the Th2-biased response towards the antigen observed with a live Lactococcus lactis vaccine that expressed tetanus toxin fragment $\mathrm{C}$ (Robinson et al., 2004). In addition, we demonstrated previously that Lactococcus lactis can induce dendritic cells to produce high levels of IL-10 in vitro (Yam et al., 2008). Therefore, Lactococcus lactis may exhibit an ability to promote Th2-type immune responses. This would account for the lack of significant protection observed against Leishmania infection, which requires Th1-type cellular immune responses for protection. In contrast, other studies have shown that Lactococcus lactis-based live vaccines can also promote balanced Th1/Th2-type immune responses (Hanniffy et al., 2007; Lee et al., 2009). As the production of IFN- $\gamma$ and the development of Th1-type immune responses are known to be required for the clearance of intracellular pathogens such as Leishmania, we could consider enhancing the antigenspecific IFN- $\gamma$ response and/or decreasing or neutralizing the IL-10 response. We are currently investigating the use of Lactococcus lactis co-expressing IL-12 and antigen to stimulate the production of antigen-specific IFN- $\gamma$.

The antigen-specific responses following immunization with A2-expressing Lactococcus lactis live vaccines may be improved by increasing the production, or increasing the size, of A2 in Lactococcus lactis. A2 is detected in Leishmania donovani as a family of proteins that range in size from 42 to $100 \mathrm{kDa}$, which corresponds to 40 to $>90$ repeats of the 10 aa motif (Ghedin et al., 1997; Zhang \& Matlashewski, 2001). Therefore, the wild-type A2 protein is much larger than the truncated A2 protein we generated, which contained ten copies of the 10 aa motif. Although the A2 epitopes of the wild-type and truncated protein are exactly the same, in the context of our Lactococcus lactis live vaccines, we may need to increase the protein size or enhance expression levels in order to augment the level of protection obtained against leishmaniasis in mice. Higher doses of antigen generally induce better antigen-specific immune responses (Grangette et al., 2004).

In summary, we have shown that it is possible to express the Leishmania A2 antigen at different subcellular locations of the Lactococcus lactis bacterium and that the expression strategy has a major influence on the type of immune response generated against this cargo antigen. The Lactococcus lactis strains generated in this study provide an excellent foundation for further studies on live bacterial vaccines against leishmaniasis and other pathogens.

\section{ACKNOWLEDGEMENTS}

We thank Dr Wen-Wei Zhang for advice and technical expertise, Raya Mahbuba for technical assistance and Dr Philippe Langella for providing the pCWA:E7 plasmid. This work was supported by a grant from the Canadian Institutes of Health Research (CIHR) to B.C. and M.O. This work was also supported in part by the Regroupements Stratégiques du Fonds Québécois de la Recherche sur la Nature et les Technologies (FQRNT). B. C. is a McGill University William Dawson Scholar and a Chercheur-Boursier Senior from Fonds de la Recherche en Santé du Québec (FRSQ). K. K. Y. was the recipient of a CIHR Canada Graduate Scholarships Master's Award, a McGill Graduate Student Fellowship and an F. C. Harrison Fellowship. G. M., M.O. and B.C. are members of the Centre for Host-Parasite Interaction (CHPI), Ste Anne de Bellevue, Quebec, Canada.

\section{REFERENCES}

Abu-Dayyeh, I., Shio, M. T., Sato, S., Akira, S., Cousineau, B. \& Olivier, M. (2008). Leishmania-induced IRAK-1 inactivation is mediated by SHP-1 interacting with an evolutionarily conserved KTIM motif. PLoS Negl Trop Dis 2, e305. 
Avall-Jääskeläinen, S., Kylä-Nikkilä, K., Kahala, M., MiikkulainenLahti, T. \& Palva, A. (2002). Surface display of foreign epitopes on the Lactobacillus brevis S-layer. Appl Environ Microbiol 68, 5943-5951.

Bahey-El-Din, M., Casey, P. G., Griffin, B. T. \& Gahan, C. G. (2008). Lactococcus lactis-expressing listeriolysin O (LLO) provides protection and specific $\mathrm{CD}^{+} \mathrm{T}$ cells against Listeria monocytogenes in the murine infection model. Vaccine 26, 5304-5314.

Beresford, T. P., Fitzsimons, N. A., Brennan, N. L. \& Cogan, T. M. (2001). Recent advances in cheese microbiology. Int Dairy J 11, 259274.

Bermúdez-Humarán, L. G., Cortes-Perez, N. G., Le Loir, Y., AlcocerGonzález, J. M., Tamez-Guerra, R. S., de Oca-Luna, R. M. \& Langella, P. (2004). An inducible surface presentation system improves cellular immunity against human papillomavirus type $16 \mathrm{E} 7$ antigen in mice after nasal administration with recombinant lactococci. J Med Microbiol 53, 427-433.

Buccato, S., Maione, D., Rinaudo, C. D., Volpini, G., Taddei, A. R., Rosini, R., Telford, J. L., Grandi, G. \& Margarit, I. (2006). Use of Lactococcus lactis expressing pili from group B Streptococcus as a broad-coverage vaccine against streptococcal disease. J Infect Dis 194, 331-340.

Casalta, E. \& Montel, M. C. (2008). Safety assessment of dairy microorganisms: the Lactococcus genus. Int J Food Microbiol 126, 271273.

Charest, H. \& Matlashewski, G. (1994). Developmental gene expression in Leishmania donovani: differential cloning and analysis of an amastigote-stage-specific gene. Mol Cell Biol 14, 2975-2984.

Coelho, E. A., Tavares, C. A., Carvalho, F. A., Chaves, K. F., Teixeira, K. N., Rodrigues, R. C., Charest, H., Matlashewski, G., Gazzinelli, R. T. \& Fernandes, A. P. (2003). Immune responses induced by the Leishmania (Leishmania) donovani A2 antigen, but not by the LACK antigen, are protective against experimental Leishmania (Leishmania) amazonensis infection. Infect Immun 71, 3988-3994.

Cortes-Perez, N. G., Bermúdez-Humarán, L. G., Le Loir, Y., Rodriguez-Padilla, C., Gruss, A., Saucedo-Cárdenas, O., Langella, P. \& Montes-de-Oca-Luna, R. (2003). Mice immunization with live lactococci displaying a surface anchored HPV-16 E7 oncoprotein. FEMS Microbiol Lett 229, 37-42.

Detmer, A. \& Glenting, J. (2006). Live bacterial vaccines - a review and identification of potential hazards. Microb Cell Fact 5, 23.

Dieye, Y., Usai, S., Clier, F., Gruss, A. \& Piard, J. C. (2001). Design of a protein-targeting system for lactic acid bacteria. J Bacteriol 183, 41574166

FDA (1995). Aminopeptidase enzyme preparation derived from lactococcus lactis. Section CFR184.1985, Code of Federal Regulations, Title 21 - Food and Drugs; Chapter I - Food and Drug Administration, Department of Health and Human Services; Subchapter B - Food for human consumption; Part 184 - Direct food substances affirmed as Generally Recognized as Safe. MD, USA: US Food and Drug Administration.

Fernandes, A. P., Costa, M. M., Coelho, E. A., Michalick, M. S., de Freitas, E., Melo, M. N., Luiz Tafuri, W., Resende, D. de M., Hermont, V. $\&$ other authors (2008). Protective immunity against challenge with Leishmania (Leishmania) chagasi in beagle dogs vaccinated with recombinant A2 protein. Vaccine 26, 5888-5895.

Fuglsang, A. (2003). Lactic acid bacteria as prime candidates for codon optimization. Biochem Biophys Res Commun 312, 285-291.

Garin, Y. J., Meneceur, P., Pratlong, F., Dedet, J. P., Derouin, F. \& Lorenzo, F. (2005). A2 gene of Old World cutaneous Leishmania is a single highly conserved functional gene. BMC Infect Dis 5, 18.

Ghedin, E., Zhang, W. W., Charest, H., Sundar, S., Kenney, R. T. \& Matlashewski, G. (1997). Antibody response against a Leishmania donovani amastigote-stage-specific protein in patients with visceral leishmaniasis. Clin Diagn Lab Immunol 4, 530-535.

Ghosh, A., Labrecque, S. \& Matlashewski, G. (2001a). Protection against Leishmania donovani infection by DNA vaccination: increased DNA vaccination efficiency through inhibiting the cellular p53 response. Vaccine 19, 3169-3178.

Ghosh, A., Zhang, W. W. \& Matlashewski, G. (2001b). Immunization with $\mathrm{A} 2$ protein results in a mixed Th1/Th2 and a humoral response which protects mice against Leishmania donovani infections. Vaccine 20, 59-66.

Grangette, C., Müller-Alouf, H., Hols, P., Goudercourt, D., Delcour, J., Turneer, M. \& Mercenier, A. (2004). Enhanced mucosal delivery of antigen with cell wall mutants of lactic acid bacteria. Infect Immun 72, 2731-2737.

Hanniffy, S. B., Carter, A. T., Hitchin, E. \& Wells, J. M. (2007). Mucosal delivery of a pneumococcal vaccine using Lactococcus lactis affords protection against respiratory infection. J Infect Dis 195, 185-193.

Kedzierski, L., Zhu, Y. \& Handman, E. (2006). Leishmania vaccines: progress and problems. Parasitology 133 (Suppl.), S87-S112.

Khamesipour, A., Dowlati, Y., Asilian, A., Hashemi-Fesharki, R., Javadi, A., Noazin, S. \& Modabber, F. (2005). Leishmanization: use of an old method for evaluation of candidate vaccines against leishmaniasis. Vaccine 23, 3642-3648.

Kuipers, O. P., Beerthuyzen, M. M., de Ruyter, P. G., Luesink, E. J. \& de Vos, W. M. (1995). Autoregulation of nisin biosynthesis in Lactococcus lactis by signal transduction. J Biol Chem 270, 2729927304 .

Kuipers, O. P., de Ruyter, P. G., Kleerebezem, M. \& de Vos, W. M. (1998). Quorum sensing-controlled gene expression in lactic acid bacteria. J Biotechnol 64, 15-21.

Le Loir, Y., Gruss, A., Ehrlich, S. D. \& Langella, P. (1998). A nineresidue synthetic propeptide enhances secretion efficiency of heterologous proteins in Lactococcus lactis. J Bacteriol 180, 1895-1903.

LeBlanc, D. J., Lee, L. N. \& Abu-Al-Jaibat, A. (1992). Molecular, genetic, and functional analysis of the basic replicon of pVA380-1, a plasmid of oral streptococcal origin. Plasmid 28, 130-145.

Lee, P., Abdul-Wahid, A. \& Faubert, G. M. (2009). Comparison of the local immune response against Giardia lamblia cyst wall protein 2 induced by recombinant Lactococcus lactis and Streptococcus gordonii. Microbes Infect 11, 20-28.

Medina, M., Villena, J., Vintiñi, E., Hebert, E. M., Raya, R. \& Alvarez, S. (2008). Nasal immunization with Lactococcus lactis expressing the pneumococcal protective protein A induces protective immunity in mice. Infect Immun 76, 2696-2705.

Mierau, I. \& Kleerebezem, M. (2005). 10 years of the nisin-controlled gene expression system (NICE) in Lactococcus lactis. Appl Microbiol Biotechnol 68, 705-717.

Miyoshi, A., Poquet, I., Azevedo, V., Commissaire, J., BermúdezHumarán, L., Domakova, E., Le Loir, Y., Oliveira, S. C., Gruss, A. \& Langella, P. (2002). Controlled production of stable heterologous proteins in Lactococcus lactis. Appl Environ Microbiol 68, 3141-3146.

Mizbani, A., Taheri, T., Zahedifard, F., Taslimi, Y., Azizi, H., Azadmanesh, K., Papadopoulou, B. \& Rafati, S. (2009). Recombinant Leishmania tarentolae expressing the A2 virulence gene as a novel candidate vaccine against visceral leishmaniasis. Vaccine $\mathbf{2 8 ,}$ $53-62$.

Piard, J. C., Hautefort, I., Fischetti, V. A., Ehrlich, S. D., Fons, M. \& Gruss, A. (1997). Cell wall anchoring of the Streptococcus pyogenes M6 protein in various lactic acid bacteria. J Bacteriol 179, 3068-3072.

Resende, D. M., Caetano, B. C., Dutra, M. S., Penido, M. L., Abrantes, C. F., Verly, R. M., Resende, J. M., Piló-Veloso, D., Rezende, S. A. \& 
Bruna-Romero, O. (2008). Epitope mapping and protective immunity elicited by adenovirus expressing the Leishmania amastigote specific A2 antigen: correlation with IFN- $\gamma$ and cytolytic activity by $\mathrm{CD}^{+}{ }^{+} \mathrm{T}$ cells. Vaccine 26, 4585-4593.

Ribeiro, L. A., Azevedo, V., Le Loir, Y., Oliveira, S. C., Dieye, Y., Piard, J. C., Gruss, A. \& Langella, P. (2002). Production and targeting of the Brucella abortus antigen L7/L12 in Lactococcus lactis: a first step towards food-grade live vaccines against brucellosis. Appl Environ Microbiol 68, 910-916.

Robinson, K., Chamberlain, L. M., Lopez, M. C., Rush, C. M., Marcotte, H., Le Page, R. W. \& Wells, J. M. (2004). Mucosal and cellular immune responses elicited by recombinant Lactococcus lactis strains expressing tetanus toxin fragment C. Infect Immun 72, 2753-2761.

Roy, G., Dumas, C., Sereno, D., Wu, Y., Singh, A. K., Tremblay, M. J., Ouellette, M., Olivier, M. \& Papadopoulou, B. (2000). Episomal and stable expression of the luciferase reporter gene for quantifying Leishmania spp. infections in macrophages and in animal models. Mol Biochem Parasitol 110, 195-206.

Scavone, P., Miyoshi, A., Rial, A., Chabalgoity, A., Langella, P., Azevedo, V. \& Zunino, P. (2007). Intranasal immunisation with recombinant Lactococcus lactis displaying either anchored or secreted forms of Proteus mirabilis MrpA fimbrial protein confers specific immune response and induces a significant reduction of kidney bacterial colonisation in mice. Microbes Infect 9, 821-828.
Stavnezer, J. (1996). Immunoglobulin class switching. Curr Opin Immunol 8, 199-205.

Steidler, L. (2003). Genetically engineered probiotics. Best Pract Res Clin Gastroenterol 17, 861-876.

Tsang, R. S. W., Nielsen, K. H. \& Johnson, W. M. (1995). Development of an indirect whole cell ELISA for the rapid identification of Salmonella. J Rapid Methods Autom Microbiol 4, 139-154.

Wells, J. M., Wilson, P. W. \& Le Page, R. W. (1993). Improved cloning vectors and transformation procedure for Lactococcus lactis. J Appl Bacteriol 74, 629-636.

Yam, K. K., Pouliot, P., N'diaye, M. M., Fournier, S., Olivier, M. \& Cousineau, B. (2008). Innate inflammatory responses to the Grampositive bacterium Lactococcus lactis. Vaccine 26, 2689-2699.

Zhang, W.-W. \& Matlashewski, G. (2001). Characterization of the A2A2rel gene cluster in Leishmania donovani: involvement of A2 in visceralization during infection. Mol Microbiol 39, 935-948.

Zhang, W.-W., Charest, H., Ghedin, E. \& Matlashewski, G. (1996). Identification and overexpression of the A2 amastigote-specific protein in Leishmania donovani. Mol Biochem Parasitol 78, 79-90.

Zhang, W.-W., Mendez, S., Ghosh, A., Myler, P., Ivens, A., Clos, J., Sacks, D. L. \& Matlashewski, G. (2003). Comparison of the A2 gene locus in Leishmania donovani and Leishmania major and its control over cutaneous infection. J Biol Chem 278, 35508-35515. 